\title{
Cutting of 316L Stainless Steel Stents by using Different Methods and Effect of Following Heat Treatment on Their Microstructures
}

\author{
Levent Oncel', Ahmet Turan², M. Ercan Acma' \\ Metallurgical and Materials Engineering Department, Faculty of Chemical and Metallurgical Engineering, \\ Istanbul Technical University, Maslak, Istanbul, Turkey ${ }^{1}$ \\ Chemical and Process Engineering Department, Faculty of Engineering, Yalova University, Yalova, Turkey ${ }^{2}$
}

\begin{abstract}
In this study, effect of different cutting methods and following normalization heat treatment on microstructure of $316 \mathrm{~L}$ stainless steel tubings were investigated. $316 \mathrm{~L}$ stainless steel is the most commonly used material for coronary stent production. Tubings were cut with laser cutting, plasma cutting, oxy-fuel cutting, water jet cutting and electrical discharge machining methods. Cut tubings were characterized by using Scanning Electron Microscope (SEM). Separate samples were prepared for heat treatment operation. 316L stainless tubings were cut with same methods and same parameters. Normalization heat treatment was applied to the samples. Heat treated tubings were characterized by using Scanning Electron Microscope. When results were evaluated, it was seen that laser cutting gives the best results rather than that of other cutting methods in terms of homogeneous microstructure, smoothness of cutting surface, a microstructure without oxidation and distortion etc.
\end{abstract}

Keywords: Biomaterials, Cutting, Heat Treatment, Microstructure, Stent, 316L.

\section{INTRODUCTION}

Implants are medical devices, which are introduced into human body to treat a disease, replace an organ or supply a function. Gold is the first known biomaterial and it was used in dentistry more than 2000 years ago by Romans, Chinese and Aztecs. Glass eyes and wooden teeth had been in common use through most of the recorded history [1].

When we look at the recent history and the present day, we see more advanced implants thanks to experiences gained from the previous implants and interdisciplinary studies. Today a wide variety of implants are produced. Implants like pacemakers, substitute heart valves, occluders, sternum wires, bare metal and drug eluting stents have great importance in the cardiology field $[1,2]$.

Stenting is the most common method for treatment of clogged arteries. Stent is a small metallic mesh tube that has ability to expand. Stent is mounted on a balloon that is opened inside of the coronary artery to push back plaque and to restore blood flow. The stent is expanded to the desired diameter. Balloon is then deflated and removed. So, stent remains in the artery and keep the artery open [3].

Shaping of stents is the first step of the production process. It has patterns less than $100 \mu \mathrm{m}$, for this reason cutting operation should be carried out precisely. Stents on the current product market generally has strut width around 75-80 $\mu \mathrm{m}$. Both sides of the strut will have the effects of the cutting process, so cutting should be done precisely to keep the microstructural change at the minimum level (Figure 1) $[4,5]$.

Laser cutting is the most common method for cutting of stents. In this method, program is loaded to laser cutting machine. This program controls the timing of the laser beam and the movement of the metal tubing. Cutting method is very important to get the desired design of the stent. After the cutting operation, the microstructure next to the cutting area and the microstructure of the same area after the subsequent heat treatment have a critical importance on the properties of the stent $[4,6]$.

Design parameters affect the mechanical properties of the stent. The effect of the design on the mechanical properties of the stent is simulated with a simulation software. Generally, a stent design includes struts and links. When balloon is expanded to desired diameter, mounted stent is also expanded. During this expansion, the angle between these struts increases, by this way struts provide homogenous distribution of plastic deformation. Links are the connectors between these struts [7]. 


\section{IARJSET

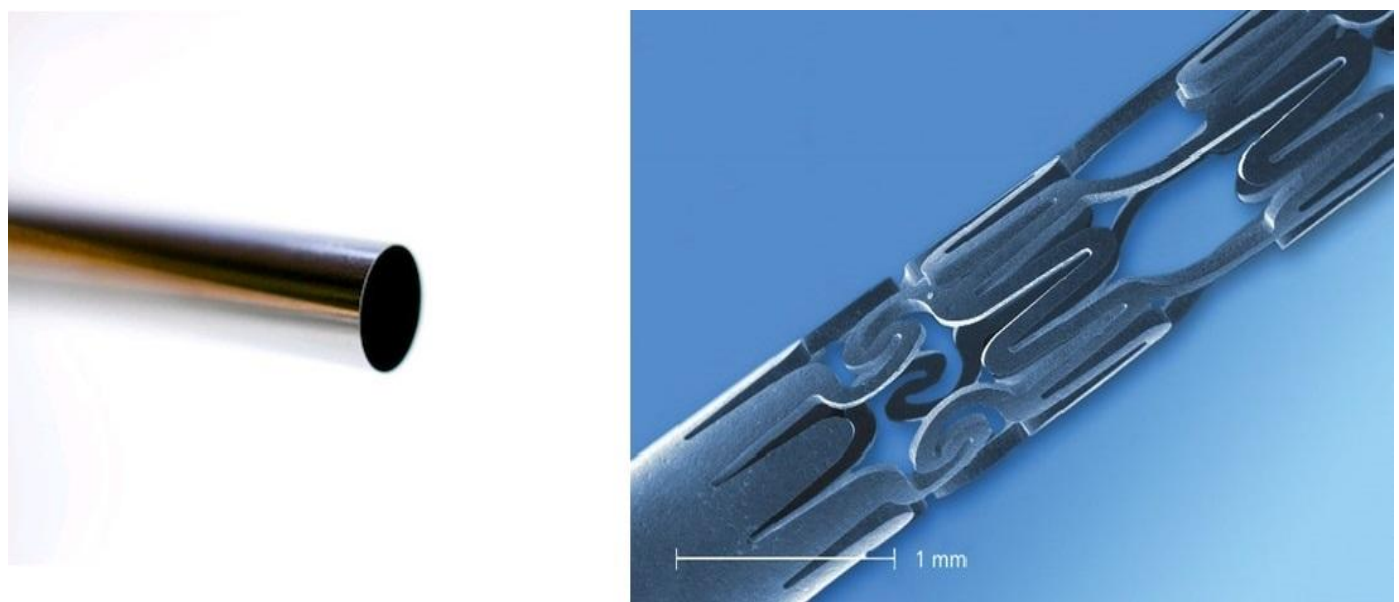

Fig. 1. 316L tubing as raw material (on the left side), after cutting operation (on the right side) $[8,9]$.

Stent's main mechanical properties are; flexibility, radial strength and fatigue resistance. Main metallurgical properties of the stent are corrosion resistance, MRI (magnetic resonance imaging) compatibility and radiopacity. Biocompatibility is another important property a stent should have. Biocompatibility properties required for the stents are cytotoxicity, genotoxicity, acute toxicity, sensitization and hemocompatibility. Biocompatibility of the stent depends on the reactions between vascular tissue and the stent as well as between blood and the stent. Stent's main interface that is in touch with both blood and vessel tissue is the metal oxide layer on the surface of the stent. That layer is created on the electro-polishing step of the stent production process. That layer generally does not interact with its environment. Good polished stent surface that have low surface roughness decreases the risk of thrombosis $[1,10,11]$.

Most common materials in stent production are 316 (316L and 316LVM) stainless steel, nitinol and cobalt-chromium alloys (L605 and MP35N). Between these materials, 316 stainless steel is the most common used material for coronary stents. 316 is an austenitic stainless steel that is easy to process. It has convenient yield strength and tensile strength for stent manufacturing. Stents, made of 316 stainless steel, are biocompatible and have low recoil ratios. There were tries to produce balloon expandable coronary stent from tantalum, martensitic nitinol, platinum and titanium. It was seen that stents produced from these materials did not meet the required properties of a coronary stent [12].

A stent must have high ductility to expand to the desired diameter without cracking. A heat affected zone occurs because of the cutting operation. Heat affects the microstructure of this zone and this zone gets relatively brittle. Heat treatment must be applied to regain the ductility of the heat affected zone. A vacuum furnace must be used in heat treatment process to avoid oxidation. Heat treatment temperature must be between $800{ }^{\circ} \mathrm{C}$ and $1000{ }^{\circ} \mathrm{C}$. Recrystallization and grain growth occurs because of the heat treatment process. In the cooling step of the heat treatment, temperatures between $450{ }^{\circ} \mathrm{C}$ and $850{ }^{\circ} \mathrm{C}$ must be passed quickly to avoid chromium carbide sensitization. Otherwise, chromium-carbide formation could occur and this could cause intergranular corrosion of the stent. 316L's low carbon content $(0.03 \%)$ minimizes the chromium carbide formation risk and consequently minimizes the intergranular corrosion possibility. Increase of the heat treatment temperature causes increase of grain size. Grain boundaries will become more distinct when grain size increases. When grain boundaries become more distinct, surface roughness of the stent will increase. Increase of the surface roughness will increase the risk of blood cell's adhesion on the stent surface and consequently thrombosis risk. As a result, an optimum temperature must be chosen in the heat treatment to get the desired mechanical properties [4,13].

In this study, 316L stainless steel tubings were cut with various cutting methods. Effects of cutting methods and subsequent heat treatment on microstructure were investigated.

\section{EXPERIMENTAL}

In this study, cutting of $316 \mathrm{~L}$ stainless steel tubing with various cutting methods was investigated. 316L stainless steel is the most commonly used material for coronary stent production. A following heat treatment was applied to the cut tubings and microstructural changes before and after heat treatment were examined.

Chemical composition and main mechanical properties of 316L stainless steel tubings were given in Table 1.

Cutting operations were performed with laser cutting, plasma cutting, oxy-fuel cutting, water jet cutting and electrical discharge machining methods. 


\section{TABLE I CHEMICAL COMPOSITION AND MECHANICAL PROPERTIES OF 316L STAINLESS STEEL}

\begin{tabular}{|c|c|c|c|}
\hline Element & Composition (wt.\%) & \multicolumn{2}{|c|}{ Mechanical Properties } \\
\hline $\mathrm{Cr}$ & 17.75 & Yield Strength & $340 \mathrm{MPa}$ \\
\hline $\mathrm{Ni}$ & 14.15 & Ultimate Yield Strength & $670 \mathrm{MPa}$ \\
\hline $\mathrm{Mo}$ & 2.72 & Elastic Modulus & $193 \mathrm{GPa}$ \\
\hline $\mathrm{Mn}$ & 1.87 & Tensile Elongation & $48 \%$ \\
\hline $\mathrm{Si}$ & 0.58 & & \\
\hline $\mathrm{P}$ & 0.015 & & \\
\hline $\mathrm{S}$ & 0.008 & & \\
\hline $\mathrm{C}$ & 0.025 & & \\
\hline $\mathrm{Fe}$ & Balance & & \\
\hline
\end{tabular}

For laser cutting, Rofin Starcut Tube Nd: Yag Laser was used, plasma cutting was carried out by using Esab M3 Water Injection Plasma, Campbell Hausfeld WT400000AV Oxyacetylene Torch Kit was used for oxy-fuel cutting, Nevtas Waterjet Model NSJ 1630 was employed for water jet cutting and EDM (electrical discharge machining) was performed by using Fanuc Robocut.

Normalization heat treatment was applied to the cut tubings in a heat treatment furnace (Carbolite HVT 15/50/450). The heat treatment parameters were temperature of $900{ }^{\circ} \mathrm{C}$ and soaking time of 1 hour under $10^{-5}$ mbar vacuum atmosphere. For SEM Characterization (scanning electron microscopy), JEOL-T330 was employed for both cut and heat treated tubings. Samples were cut with above mentioned methods. Laser cutting is the standard cutting method for stent production; therefore, two different cutting parameters were used for this method. In the first cutting, laser beam energy was $1.17 \mathrm{~mJ}$ and frequency was $3500 \mathrm{~Hz}$, in the second cutting $0.91 \mathrm{~mJ}$ laser beam energy and $5500 \mathrm{~Hz}$ frequency was used.

In the plasma cutting, water injection plasma cutting method was used. For plasma cutting, plasma gas was mixture of air and oxygen under pressure of 4 bar. Zirconium was used as cathode material. Current was $70 \mathrm{~A}$ and voltage was 80 V. In oxy-fuel cutting, cutting gas was oxygen. In water jet cutting, water pressure was 4000 bars and garnet was used as abrasive material. In electrical discharge machining, copper electrode was used. Current was $10 \mathrm{~A}$, pulse on time was $1.1 \mu \mathrm{s}$ and pulse off time was $12 \mu \mathrm{s}$.

Cut samples were mounted in bakelite. 1000 and 2500 polishing grits were applied and alumina powders were used in the polishing stage of the samples. Then, samples were electro-etched for 30 seconds using $10 \%$ oxalic acid. DC power source and $6 \mathrm{~V}$ voltage were used in the electro-etching step. After polishing of the cut samples, micrographs were taken by using scanning electron microscope. Considering the oxidation possibility during cutting operations, samples, that were going to be heat treated, were held in acid solution consisted of hydrofluoric acid, nitric acid and deionized water.

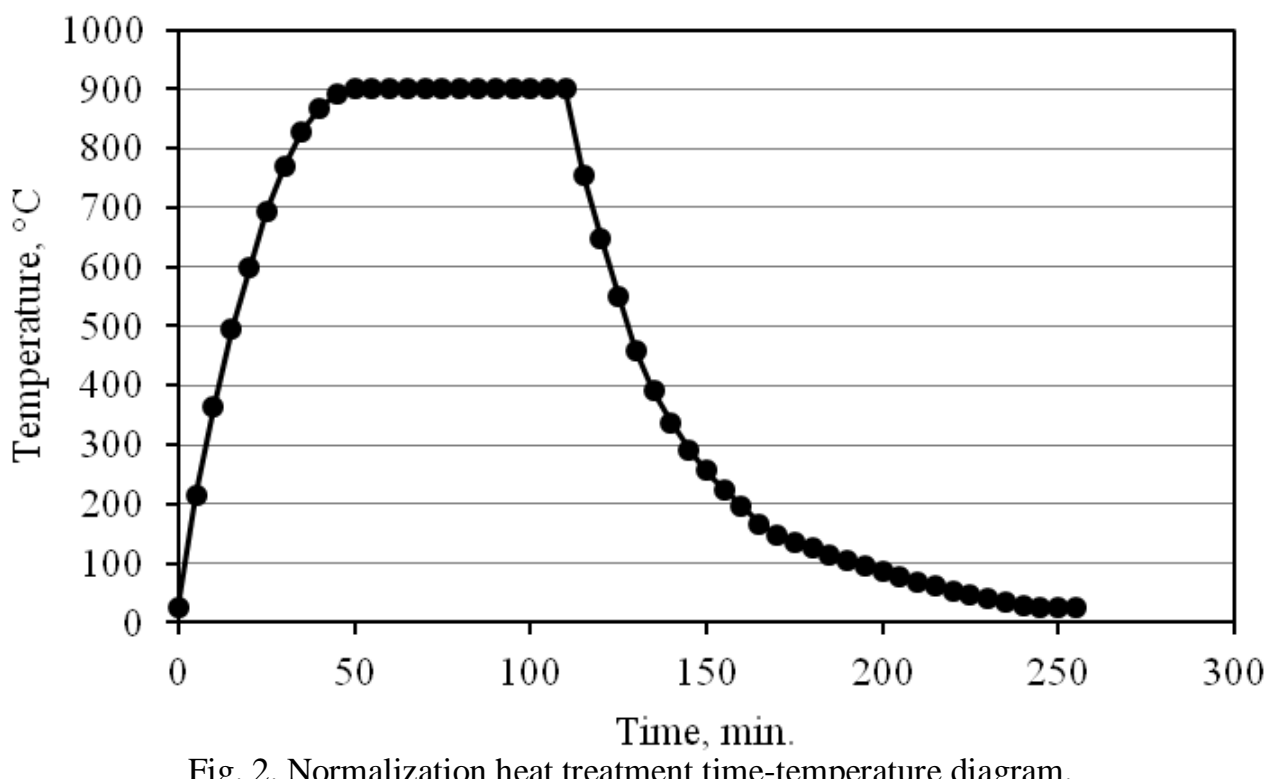




\section{IARJSET

Acid solution's temperature was $50{ }^{\circ} \mathrm{C}$ and holding time was 5 minutes. An ultrasonic cleaner was used to increase the efficiency of the oxide removing. Separate samples were prepared for heat treatment operation. 316L stainless steel tubings were cut with same methods and same parameters. After holding in acid solution, normalization heat treatment was applied to the samples. Normalization heat treatment parameters were shown in Figure 2. Grinding, polishing and electro-etching steps were carried out with the same parameters. Micrographs of the heat-treated samples were taken by using scanning electron microscope. Micrographs of cut samples and heat-treated samples were evaluated and compared with each other.

\section{RESULTS AND DISCUSSION}

Figure 3 shows SEM micrographs of the tubings cut with laser cutting method with different parameters; laser cutting with $1.17 \mathrm{~mJ}$ laser beam energy and $3500 \mathrm{~Hz}$ frequency (A1 and A2), laser cutting with $0.91 \mathrm{~mJ}$ laser beam energy and $5500 \mathrm{~Hz}$ frequency (B1 and B2). A1 and B1 are the SEM micrographs after cutting operation. A2 and B2 are the SEM micrographs of heat treated cut tubings. Figure 4 shows the SEM micrographs of the tubings cut with various cutting methods other than laser; plasma cutting (C1 and C2), oxy-fuel cutting (D1 and D2), water jet cutting (E1 and E2) and electrical discharge machining (F1 and F2). C1, D1, E1 and F1 are the SEM micrographs after cutting operation. C2, D2, E2 and F2 are the SEM micrographs of heat treated cut tubings.
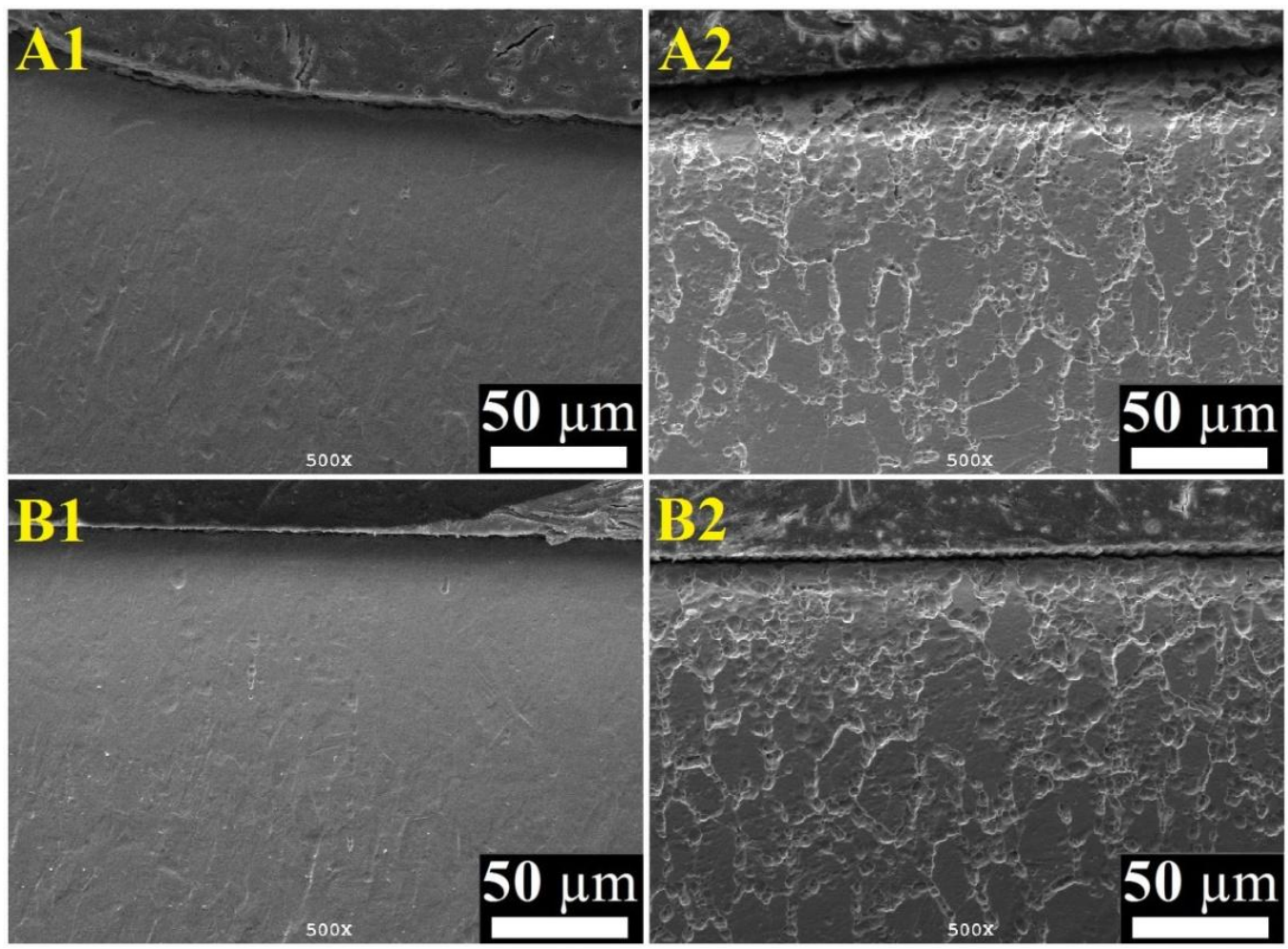

Fig. 3. SEM micrographs of laser cut 316L tubings $[1.17 \mathrm{~mJ}-3500 \mathrm{~Hz}$ : (A1) before heat treatment, (A2) after heat treatment; $0.91 \mathrm{~mJ}-5500 \mathrm{~Hz}$ (B1) before heat treatment (B2) after heat treatment].

As it can be seen from Figure 3 (A1), laser cutting with $1.17 \mathrm{~mJ}$ laser beam energy and $3500 \mathrm{~Hz}$ frequency created a heat affected zone about $10 \mu \mathrm{m}$. In this zone, grains are smaller because of the recrystallization. (A2) shows that normalization heat treatment created more homogenous microstructure. (B1) illustrates that laser cutting with $0.91 \mathrm{~mJ}$ laser beam energy and $5500 \mathrm{~Hz}$ frequency created a heat effected zone as the laser cutting with different parameters. Heat affected zone for these laser cutting parameters is about $20 \mu \mathrm{m}$. Recrystallization in this zone caused formation of smaller grains. After heat treatment, microstructure became more homogenous.

In Figure $4(\mathrm{C} 1)$, it is seen that plasma cutting created a heat affected zone about $200 \mu \mathrm{m}$. There are smaller grains in this zone because of the recrystallization. Using of oxygen and air mixture in the cutting operation created oxidation at the grain boundaries. In addition, a low quality cutting surface was obtained. As seen (C2), holding the cut tubing in the acid solution prior to heat treatment removed oxides. Despite the applied heat treatment, grains in the heat affected zone are still smaller than the rest of the microstructure. (D1) shows that oxy-fuel cutting created heat affected zone between $100 \mu \mathrm{m}$ and $200 \mu \mathrm{m}$. Grains are smaller in this zone. 

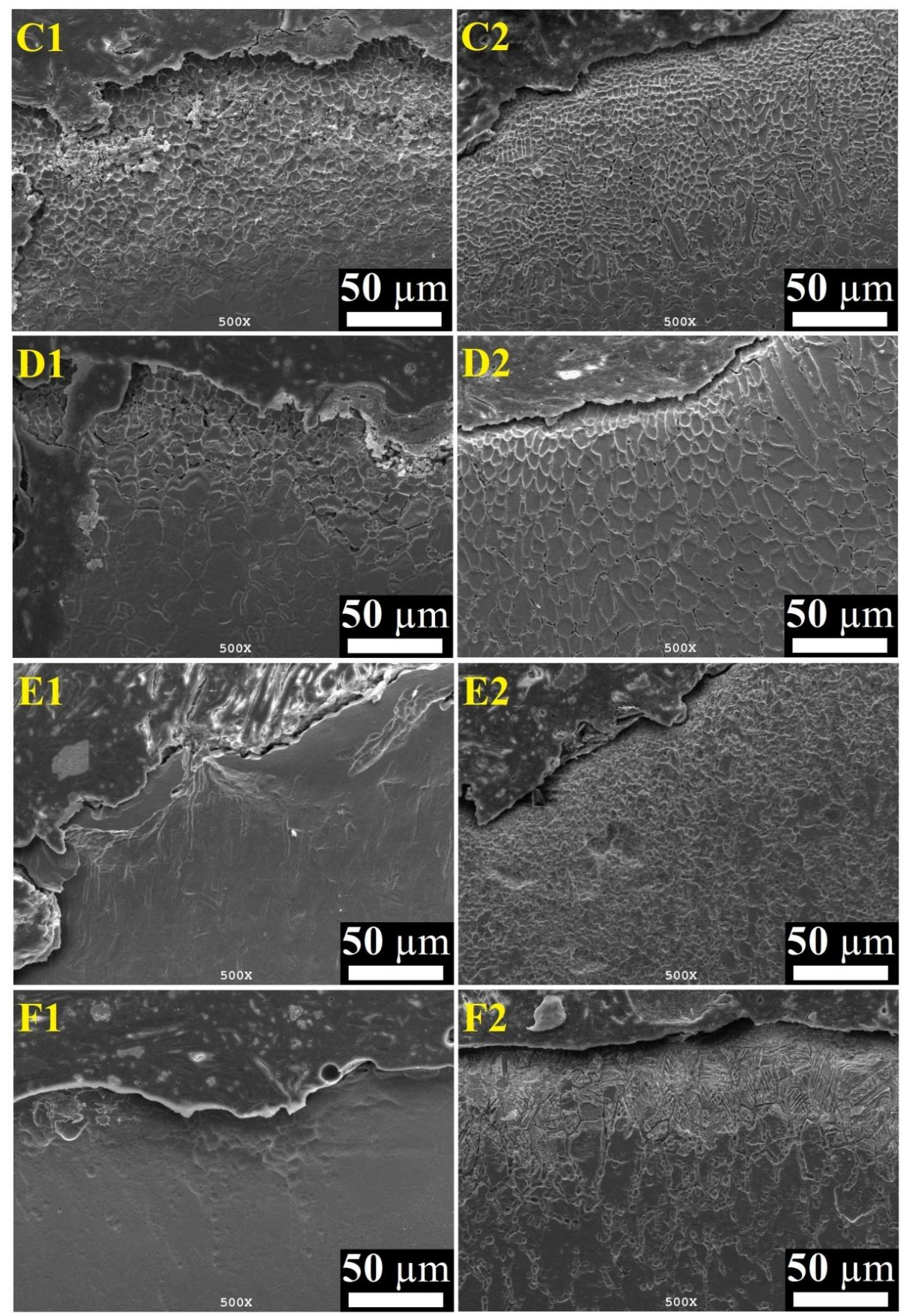

Fig. 4. SEM micrographs of cut 316L tubings by using different cutting methods [(C) Plasma cutting, (D) Oxy-fuel cutting, (E) Water jet cutting, (F) Electrical discharge machining. Numbered with (1) shows the micrographs taken before heat treatment, (2) after heat treatment].

It is seen that oxy-fuel cutting created oxidation and voids at the grain boundaries. (D2) illustrates that holding the cut tubing in acid solution prior to heat treatment removed oxides from the grain boundaries. Applied heat treatment did not change the size of the grains in the heat affected zone; they are still smaller than the rest of the structure. In (E1), it is seen that garnet, which was used as abrasive material in water jet cutting, deflected from the cutting area and damaged a wide area. This damage could lead to crack initiation in the structure. In addition, water jet cutting method created distortion on the structure because of the cutting method's nature. Water jet cutting method does not produce heat, for this reason heat treatment did not change the structure of the cut tubing [Figure 3 (E2)]. Figure 3 (F1) shows that electrical discharge machining created amorphous structure near the cutting zone. This amorphous zone is the result of sudden heating and cooling in the cutting process. (F2) illustrates that heat treatment caused recrystallization and grain growth. Annealing twins can be seen in the microstructure. After heat treatment, grain size became nearly homogenous throughout the material. 


\section{IARJSET

When results are evaluated, it is seen that laser cutting is the best cutting method for producing stent. Laser cutting created a heat affected zone between $10 \mu \mathrm{m}$ and $20 \mu \mathrm{m}$ depending on the cutting parameters used. Recrystallization in heat affected zone caused formation of smaller grains. After normalization heat treatment, homogenous microstructure was obtained. Plasma cutting and oxy-fuel cutting created heat affected zones about $200 \mu \mathrm{m}$. In heat affected zones, grain sizes are smaller than the rest of the material. Stents have patterns less than $100 \mu \mathrm{m}$ and these values are unacceptable. Normalization heat treatment did not have an effect on heat affected zone. After heat treatment, grains are still smaller than rest of the material. Another disadvantage of these methods was oxidation at the grain boundaries. In these cutting methods, oxides were removed by holding the 316L stainless steel tubings in an acid solution prior to heat treatment. Water jet cutting created distortion on the material. Deflection of garnet (abrasive material) from the cutting zone is another disadvantage of water jet cutting. Damage created by garnet could lead to a crack initiation on the $316 \mathrm{~L}$ stainless steel tubing. Electrical discharge machining (EDM) created an amorphous region about $100 \mu \mathrm{m}$. Normalization heat treatment caused recrystallization and grain growth. In addition, annealing twins formed because of heat treatment. Annealing twins act like grain boundaries and this is an adverse condition for stent production. When smoothnesses of the cutting surfaces are compared, laser cutting method produced the best results. While not as good as laser cutting, electrical discharge machining produced acceptable results. Smooth surfaces could not be obtained in plasma cutting, oxy-fuel cutting and water jet cutting methods.

Between two laser cutting parameters, cutting with $1.17 \mathrm{~mJ}$ laser beam energy and $3500 \mathrm{~Hz}$ frequency created a narrower heat affected zone compared to $0.91 \mathrm{~mJ}$ laser beam energy and $5500 \mathrm{~Hz}$ frequency. Increasing of frequency widened the heat affected zone. After normalization heat treatment, similar microstructures were obtained.

\section{CONCLUSIONS}

In the present study, the most commonly used raw material of coronary stents, $316 \mathrm{~L}$ stainless steel tubings were cut with various methods including laser cutting, plasma cutting, oxy-fuel cutting, water jet cutting and electrical discharge machining. After cutting operations were completed, samples were characterized by using SEM.

Separate samples were prepared for normalization heat treatment operation. 316L stainless steel tubings were cut with same methods and same parameters. After cutting operation was completed, normalization heat treatment was applied on the samples. Heat treated tubings were characterized by using SEM.

When results are evaluated, it is seen that laser cutting gives the best results between these cutting methods. Laser cutting provided a smooth surface with good precision of cutting. There were not oxide formations during the cutting. In addition, after normalization heat treatment, grains become homogenous through the material. It was determined that between the cutting methods in question, only laser cutting can produce the pattern of the stents.

For production of medical implants which require less precision and surface smoothness, electrical discharge machining can be an alternative to laser cutting. Electrical discharge machining can create complex geometries with good surface quality. Slow rate of material removal must be taken into consideration. Plasma cutting, oxy-fuel cutting and water-jet cutting methods did not produce acceptable surface quality and had negative effects on the microstructures. Water jet cutting created distortion and abrasive material used in the cutting operation damaged the material. In laser cutting, using more laser beam energy and less frequency created a narrower heat affected zone. After following normalization heat treatment, similar microstructures were obtained for both laser beam energy and frequency values.

\section{REFERENCES}

[1] Ratner, B. D., Hoffman, A. S., Schoen, F. J, Lemons, J. E., Biomaterials Science: An Introduction to Materials in Medicine, Academic Press, California, USA, 1996.

[2] Davis, J. R., Handbook of Materials for Medical Devices, ASM International, Ohio, USA, 2003.

[3] Morgan, R. A., Walser, E., Handbook of Angioplasty and Stenting Procedures, Springer, London, UK, 2010.

[4] Oncel, L., "Characterization of Cutting Methods and Annealing of 316L Stainless Steel Implants", M.Sc. Thesis, Istanbul Technical University, Istanbul, Turkey, June 2009.

[5] Muhammad, N., Whitehead, D., Boor, A., Li, L., "Comparison of dry and wet fiber laser profile cutting of thin 316L stainless steel tubes for medical device applications", J. of Mater. Process. Tech. 210, 2261-2267, 2010.

[6] Arslan, E., "Stent Manufacturing and Investigation of the Mechanical and Corrosive Properties of Plasma Nitrizidated Stent and Stent Material", M.Sc. Thesis, Istanbul Technical University, Istanbul, Turkey, Aug. 2005.

[7] Bonsignore, C., "A decade of evolution in stent design" in Proceedings of the International Conference on Shape Memory and Superelastic Technologies, California, USA, 2003.

[8] URL 1: http://www.vascotube.com/

[9] URL 2: http://www.medicaldevice-network.com/

[10] Balcon, R., Beyar, R., Chierchia, S., Scheerder, I. D., Hugenholtz, P. G., Kiemeneij, F., Meier, B., Meyer, J., Monassier, J. P., Wijns, W., "Recommendations on stent manufacture, implantation and utilization", EUR. HEART J. 18, 1536-1547. 1997.

[11] Steinemann, S. G., "Metal implants and surface reactions", Injury 27, 16-21, 1996.

[12] McLean, D. R., Eigler, N.L., "Stent design: implications for restenosis", Rev. Cardiovasc. Med. 3 (Suppl 5), 16-22, 2002.

[13] Zhao, H., Humbeeck, J. V., Sohier, J., Scheerder, I. D., "Electrochemical polishing of 316L stainless steel slotted tube coronary stents", J. Mater Sci-Mater. M. 13, 911-916, 2002. 